\title{
Pathogenic Variation and Molecular Characterization of Pyricularia oryzae, Causal Agent of Rice Blast Disease in Tanzania
}

\author{
Charles Joseph Chuwa ${ }^{1}$, Robert B. Mabagala ${ }^{2}$, Mnyuku S.O.W. Reuben ${ }^{3}$ \\ ${ }^{1,2,3}$ Sokoine University of Agriculture (SUA), Department of Crop Science and Production, Morogoro, Tanzania
}

\begin{abstract}
Rice blast disease, caused by the fungus Pyricularia oryzae, is one of the most devastating diseases of rice. Understanding pathogenic variation and molecular characterization of $P$. oryzae is one of the most efficient ways to manage the disease. Studies on identification, characterization and pathogenic variation of $P$. oryzae were conducted in the laboratory and screen-house at Sokoine University of Agriculture, Morogoro. Seven P. oryzae strains collected from Shinyanga, Kilimanjaro, Mbeya and Morogoro were tested with a set of ten rice blast differentials viz; IRBLk-Ka, IRBLkm-Ts, IRBLb-w/co, IRBLkp-K60, IRBLz-Fu, IRBLa-C, IRBLi-F5, IRBLta2-Pi), St and IRBLt-K59. Twenty one-day-old seedlings grown in pots were inoculated with spore suspension of a P. oryzae at a concentration of $2 \times 10^{5} \mathrm{ml}^{-1}$ using a hand-hold sprayer in the evening. Considerable pathogenic variations among the tested strains were observed. The International rice differentials IRBLk-Ka, IRBLkp-K60, IRBLa-C, IRBLi-F5, IRBLta2-Pi, St and IRBLt-K59 were resistant to all strains, however, IRBLb-w/co, IRBLkm-Ts and IRBLz-Fu (Piz) were susceptible. Molecular analysis using four primers Bt1a and Bt1b, CAL-228F and CAL-737R, ACT-512F and ACT-783R, ITS1 and ITS4 were used for amplification of seven P. oryzae strains. The results showed no differences in banding patterns between strains, indicating that all strains analyzed were genetically homogeneous but pathogenically heterogeneous.
\end{abstract}

Keywords: Characterization, pathogenic variation, PCR, Pyricularia oryzae

\section{Introduction}

Rice is one of the most important cereal crops grown worldwide. In Tanzania, more than a half of the population depends on rice as the main food and source of income. Rice blast disease is the most important and destructive disease of rice. It is caused by the fungus Pyricularia oryzae (Teleomorph Magnaporthe oryzae Couch) formally known as Pyricularia grisea (Cooke) Sacc.] [8], [38], [15] [Teleomorph Magnaporthe grisea (Herbert)]. The incidence and severity of rice blast disease vary yearly based on location and environmental conditions [46], [35], [3]. Symptoms of the disease can occur on all above ground parts of the plant and is observed at earlier growing stages up to maturity. Symptoms appear on the leaves, nodes and panicles [14], [38]. It has been reported to cause grain yield losses of up to $100 \%$ [31], [11], [40].

However, P. oryzae [anamorph] Cavara has been reported to have high pathogenic variation with respect to host range and variety specificity [24]. The level of pathogenic variation of $P$. oryzae isolates differs with rice varieties [4]. Therefore, the studies on reaction of differential rice genotypes and molecular characterization are important in understanding pathogenic variation of $P$. oryzae. Rice blast disease can be classified into various pathotypes based on the infection pattern observed on a set of differential rice genotypes [20].

The use of resistant rice varieties is the most economical and effective means of managing blast disease in rice [6], [14]. However, sometimes resistant varieties may become ineffective due to evolutionary changes in the pathogen population [22]. Loss of resistance shortly after variety release is common in many rice growing areas [20]. Therefore, understanding pathogenic variation of $P$. oryzae is important in overcoming constraints facing many rice breeding programs [7].

Pathogenic variation is the main cause of resistance breakdown in rice against rice blast disease [37]. Several studies have reported different sources of pathogenic variation in $P$. oryzae. Great pathogenic variation has been reported in $P$. oryzae from single-spore isolates originating from single lesions and monoconidial sub-cultures [7]. The isolates from the same lesion may differ in pathogenicity, and single-spore subcultures may also differ in pathogenicity from the original single-spore cultures [12]. However, the composition of groups of isolates that are genetically different may cause variation in the pathogen [4]. [22] reported that variation in the pathogen is caused by variation in chromosome numbers or genomic rearrangements. Similarly, [44], [45] reported that parasexual recombination is one of the means of variation in $P$. oryzae. Further understanding of pathogenic changes during sexual hybridization may provide evidence to pathogenic variation observed in the asexual stage of the fungus.

Pyricularia oryzae strains are not pathogenically homogenous, existence of pathogenic races has been reported from many major rice growing countries [1]. However, such variation in Tanzania has not yet been studied. [1] identified about five pathogenic race groups, ID1, ID-2, IB-4, IC-17 and IC-25. Among these groups, physiologic race group IC-17 was observed to be predominant. [28] investigated 31 isolates of the fungus in India, of which 21 isolates belonged to a new race group designated as IJ, and the rest belonged to the international race groups. Their study identified races IC 3 and ID 1 as common in India. In Brazil, a great number of physiological races with distinct virulence characteristics have been identified based on reaction types on a set of eight standard 


\section{International Journal of Science and Research (IJSR) \\ ISSN (Online): 2319-7064 \\ Index Copernicus Value (2013): 6.14 | Impact Factor (2014): 5.611}

international rice differentials [29]. Races IC-1 and IB-9 were reported to be predominant in Brazil.

A culture of $P$. oryzae may change its pathogenicity but it can not be used as the criteria of assigning pathogenic race [41]. In a study of [41] categorized pathogenic isolates by assessing the reaction of rice varieties with respect to blast disease, and came up with three categories namely; resistance, moderate resistance and susceptible rice varieties. The use of differential rice genotypes of blast disease is widely adapted as the technique for distinguishing pathogenic races of pathogens.

Molecular studies are currently appropriate approaches in identification and characterization of $P$. oryzae [12]. However, the use of DNA technologies such as polymerase chain reaction (PCR) is the most important approach in detection of the pathogen [2], [6], [9]. The PCR technique is effective for distinguishing between closely related isolates. The aim of this study was to identify, characterise and determine of pathogenic variation of $P$. oryzae using a set of rice differentials as well as PCR techniques.

\section{Materials and Methods}

\subsection{Source of isolates}

Rice leaves and panicles with blast lesions were collected from Mbeya, Morogoro, Shinyanga and Kilimanjaro regions in Tanzania. A total of 320 rice blast disease samples were collected in the brown paper bags and transferred to the African Seed Health Centre laboratory at SUA for isolation, identification and characterization of the rice blast pathogen.

\subsection{Isolation and identification of Pyricularia oryzae}

Infected tissues (lesions) were sterilized using $1 \%$ Sodium hypochlorite for 1 minute to reduce saprophytes, and then rinsed in distilled water three times. Each lesion was placed on moistened filter papers in Petri dishes and incubated for 72 hours ( 3 days) at $25{ }^{\circ} \mathrm{C}$ to allow for fungal sporulation on the lesions [4]. Identification of $P$. oryzae was done three days after incubation based on morphological features as described by [13], [18]. Conidia were identified from the sporulating lesions using a stereomicroscope and identity confirmed following procedures of [23].

Thereafter, sterile drawing pins were dipped in potato dextrose agar (PDA) petri plates and then slightly touched on the sporulating rice blast lesions, followed by inoculation of the agar plates with the pin containing spores of the presumed $P$. oryzae. Then the pathogen was cultured in petri dishes on PDA agar, incubated at $25 \pm 1{ }^{\circ} \mathrm{C}$ to induce sporulation as described by [33]. After sporulation, the conidia were harvested by adding $10 \mathrm{ml}$ of sterilized distilled water per petri plate and gently scraped the surface to harvest the spores. Conidial suspensions at a concentration of about $10^{4}$ spores $/ \mathrm{ml}$ were prepared in sterilized distilled water with $0.1 \%$ Tween 20 to increase spore dispersion [32]. Conidial densities were counted using a haemocytometer. Established cultures were subsequently maintained [39] and used for further studies as and when required.

\subsection{Determination of pathogenic variation of Pyricularia} oryzae by host differentials

The experiment was conducted in the screen house at SUA to assess virulence (aggressiveness) of $P$. oryzae isolates on a set of ten rice blast differential monogenic varieties and to distinguish the pathogen pathotypes (races). These differentials included IRBLk-Ka (Pik), IRBLkm-Ts $(P i k-m)$, IRBLb-w/co, IRBLkp-K60 (Pik-p), IRBLz-Fu (Piz), IRBLaC (Pia), IRBLi-F5 (Pii), IRBLta2-Pi (Pita-2), St and IRBLtK59 (Pit) and were collected from AfricaRice Tanzania office.

Four hundred seeds for each variety as recommended by [17] were sown in eight $15 \mathrm{~cm}$ diameter plastic pots containing sterilized moist silt loam soil arranged in a Completely Randomised Design (CRD) with three replicates. Fifty seeds were sown in each pot, each pot represented one replication. Inoculum preparation was done as described by [36]. Rice seedlings were inoculated with $P$. oryzae at the 4-5 leaf stage (21-day-old seedlings) in the evening using a low-pressure spray bottle with a suspension of conidia $2 \times 10^{5}$ spores $/ \mathrm{ml}$ following procedures described by [46]. Disease reaction was assessed seven to ten days after inoculation based on the [16] standard evaluation scale of $0-9$ where: $0=$ no lesions; $1=$ small, brown, specks of pinhead size; $3=$ small, roundish to slightly elongated, necrotic, gray spots about $1-2 \mathrm{~mm}$ in diameter; 5 = typical blast lesions infecting $<10 \%$ of the leaf area; $7=$ typical blast lesions infecting $26-50 \%$ of the leaf area; $9=$ typical blast lesions infecting $>51 \%$ leaf area and many dead leaves [43]. The pathogenic race of each isolate was determined by the reaction of the rice differential varieties used.

\subsection{Characterization of Pyricularia oryzae by PCR}

\subsubsection{DNA extraction}

Total DNA was extracted from seven isolates of $P$. oryzae. The pathogen isolates were grown on $10 \mathrm{~g}$ of potato dextrose agar supplemented with $2 \mathrm{~g}$ of yeast extract per liter in Erlenmeyer flasks for hours without agitation followed by ten days with constant agitation in the darkness at $24{ }^{\circ} \mathrm{C}$. One or two mycelial paper discs were transferred to $250 \mathrm{ml}$ Erlenmeyer flasks containing $150 \mathrm{ml}$ of the culture medium. The harvested mycelia was freeze-dried, lyophilized and macerated in liquid nitrogen. DNA extraction was done following the procedure described by [29].

About $300 \mathrm{mg}$ of powdered mycelia was suspended in $700 \mu \mathrm{l}$ of extraction buffer $(50 \mathrm{mM}$ Tris- $\mathrm{HCl}, \mathrm{pH} 8.0 ; 50 \mathrm{mM}$ EDTA; $3 \%$ sodium dodecyl sulfate, wt/vol and $1 \%$ of mercaptoethanol) at $65{ }^{\circ} \mathrm{C}$ for 1 hour. The cellular proteins were precipitated with $30 \mu \mathrm{l}$ of potassium acetate $(3 \mathrm{M}$ and $\mathrm{pH}$ 5.2). DNA was precipitated in $200 \mu \mathrm{l}$ of cold isopropanol, washed with $70 \%$ ethanol, dried under vacuum and re-suspended in TE buffer (10 mM Tris-HCl, $\mathrm{pH} 8.0 ; 1.0$ $\mathrm{mM}$ EDTA), containing $10 \mathrm{mg} / \mathrm{ml}$ of RNase A and incubated at $37^{\circ} \mathrm{C}$ for $30 \mathrm{~min}$. The DNA concentration was estimated by fluorometer and adjusted to $10 \mathrm{ng} / \mu \mathrm{l}$. The DNA pellets were dried overnight and dissolved in $1 \mathrm{ml}$ of TE buffer $(\mathrm{pH}$ 8.0). Quantification of DNA was performed on $0.8 \%$ agarose gel and diluted with sterile distilled water to a concentration of $25 \mathrm{ng}$ for PCR analysis. The PCR contained 


\section{International Journal of Science and Research (IJSR) \\ ISSN (Online): 2319-7064 \\ Index Copernicus Value (2013): 6.14 | Impact Factor (2014): 5.611}

the following reaction mixture $(25 \mu \mathrm{l}): 50 \mathrm{ng}$ DNA, $2.5 \mu \mathrm{l} 10$ $\mathrm{x}$ buffer reaction $(200 \mathrm{mM}$ Tris-HCL, Ph 8.4 and $500 \mathrm{mM}$ of $\mathrm{KCL}), 2.0 \mu \mathrm{l} 50 \mathrm{mM}, \mathrm{MgCL}_{2} ; 0.5 \mu \mathrm{ldNTP}(10 \mathrm{mM}$ each dATP, dGTP, dCTP and dTTP); $1.25 \mu$ of each primer (100 $\mathrm{mM}) ; 5$ units of Taq polymerase.

\subsubsection{Polymerase chain reaction (PCR) amplification}

The PCR amplification reaction was carried out in a thermocycler with the following temperature conditions as described by [5] with modifications. An initial PCR cycle was performed at $95{ }^{\circ} \mathrm{C}$ for 4 minutes, primer annealing at 55 ${ }^{\circ} \mathrm{C}$ for $30 \mathrm{~s}$, polymerization at $72{ }^{\circ} \mathrm{C}$ for 1 minute. This was followed by 30 cycles of $94{ }^{\circ} \mathrm{C}$ for 5 minutes, $55{ }^{\circ} \mathrm{C}$ for $30 \mathrm{~s}$ and $72{ }^{\circ} \mathrm{C}$ for 1 minute. Final extension was performed at 72 ${ }^{\circ} \mathrm{C}$ for 7 minutes. The PCR products were separated in agarose gel electrophoresis $2 \%$ in TBE $0.5 \mathrm{x}$ with 100 volts for 30 minutes (Figure 1) then visualized in UV light after soaking in ethidium bromide. Four primers (Table 1) were used to amplify the targeted DNA fragments.

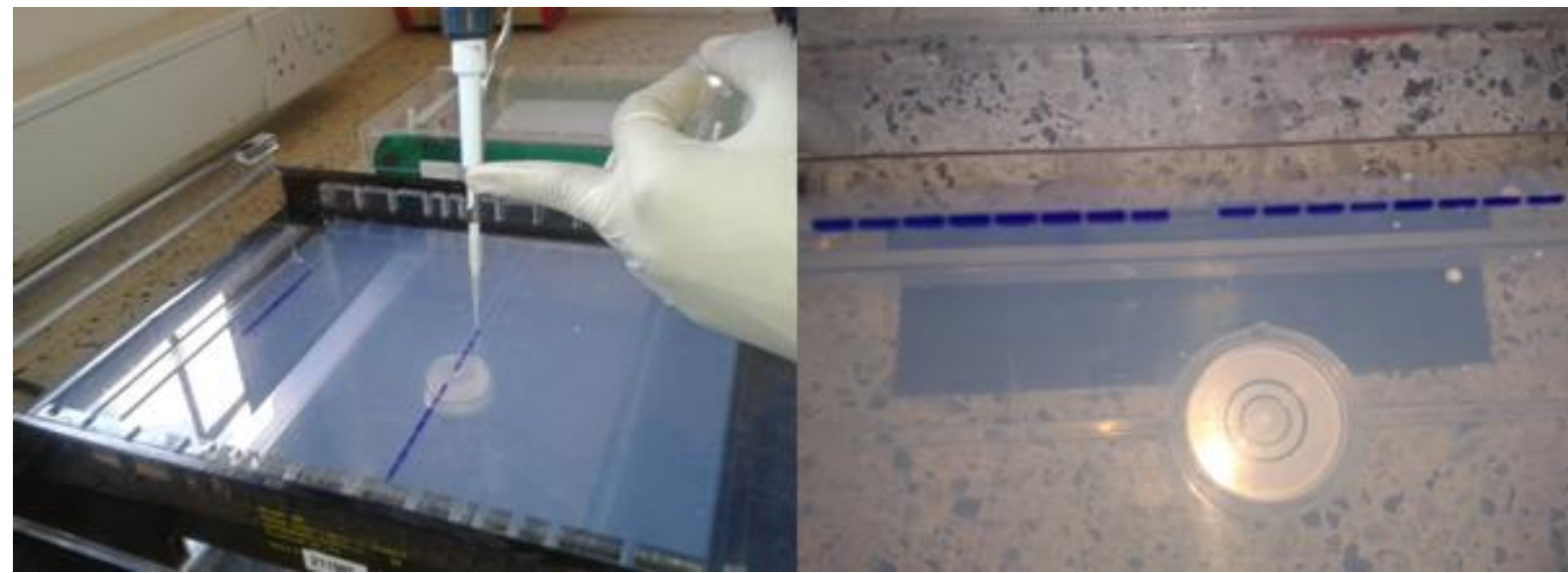

Figure 1: Loading of DNA in the agarose jel for amplification (photos: C. J. Chuwa, MARI, Dar es Salaam).

\subsubsection{Statistical Analysis}

Data were analyzed using both GenStat ${ }^{\circledR}$ Executable release 14 Statistical Analysis Software Microsoft Excel. Data were subjected to analysis of variance (ANOVA) tests. When significant differences were found, means were separated and assessed using Duncan's Multiple Range Test (DMRT). Significant differences between treatment means were tested using the Least Significant Difference (LSD) at $5 \%$ level of probability. The dendrogram was constructed with UPGMA cluster analysis of all seven isolates studied using simple similarity coefficients.

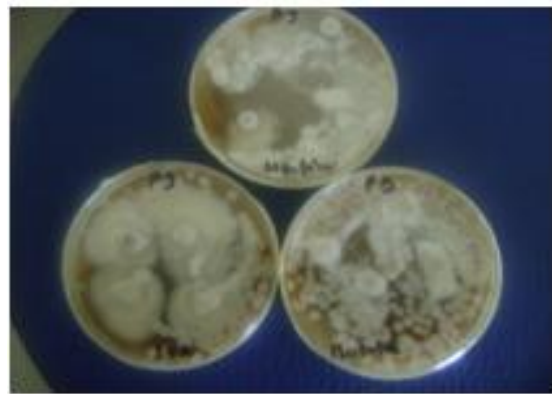

a)

\section{Results and Discussion}

\subsection{Identification and pathogenicity test of Pyricularia oryzae}

Of the 320 isolates of rice blast disease collected, only seven strains were identified as Pyricularia oryzae based on morphology and PCR. The pathogen P. oryzae obtained from the blotter method was cultured on PDA medium. The strains from leaf component DAK, KAH, KAP, KIK, MOS, MSU and SUA showed excellent sporulation and growth on PDA medium (Figure 2a). These results correspond with the study [15] found that PDA containing segments of rice leaf, better favored the growth of $P$. oryzae. Conidial variation of the $P$. oryzae isolates used was not identified in the study. Conidia were pyriform, almost hyaline to pale olive, 2-septate and 3celled (Figure 2b).

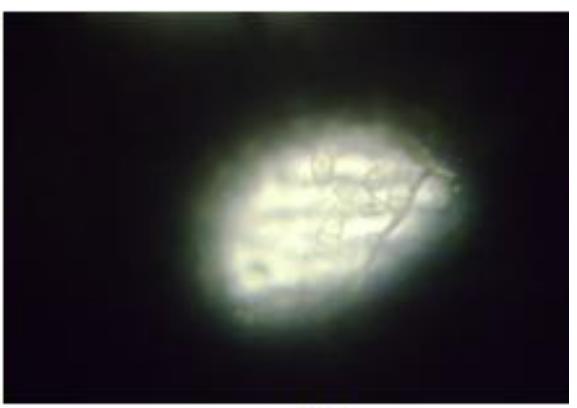

b)

Figure 2: a) Colony growth and b) conidia morphology of the three isolates Pyricularia oryzae (photos: C. J. Chuwa, SUA, Morogoro). 


\subsection{Pathogenic variation of Pyricularia oryzae using rice differentials}

The $P$. oryzae strains pathotyped by inoculation on the international rice differentials showed compatible reactions (Table 1). The International rice differentials IRBLk-Ka
(Pik), IRBLkp-K60 (Pik-p), IRBLa-C， IRBLi-F5 (Pii), IRBLta2-Pi (Pita-2), St and IRBLt-K59 (Pit) were resistant to all $P$. oryzae strains. However, differentials IRBLb- w/co, IRBLkm-Ts (Pik-m) and IRBLz-Fu (Piz) were susceptible.

Table 1: Reaction of differential rice varieties to seven strains of Pyricularia oryzae collected from Kilimanjaro, Mbeya, Morogoro and Shinyanga regions in Tanzania

\begin{tabular}{lccccccc}
\hline Differential & DAK & KAH & KAP & $\frac{\text { Strains }}{\text { KIK }}$ & MOS & MSU & SUA \\
\hline IRBLk-Ka & $\mathrm{R}$ & $\mathrm{R}$ & $\mathrm{R}$ & $\mathrm{R}$ & $\mathrm{R}$ & $\mathrm{R}$ & $\mathrm{R}$ \\
IRBLa-C & $\mathrm{R}$ & $\mathrm{R}$ & $\mathrm{R}$ & $\mathrm{R}$ & $\mathrm{R}$ & $\mathrm{R}$ & $\mathrm{R}$ \\
St & $\mathrm{R}$ & $\mathrm{R}$ & $\mathrm{R}$ & $\mathrm{R}$ & $\mathrm{R}$ & $\mathrm{R}$ & $\mathrm{R}$ \\
IRBLkp-K60 & $\mathrm{R}$ & $\mathrm{R}$ & $\mathrm{R}$ & $\mathrm{R}$ & $\mathrm{R}$ & $\mathrm{R}$ & $\mathrm{R}$ \\
IRBLt-K59 & $\mathrm{R}$ & $\mathrm{R}$ & $\mathrm{R}$ & $\mathrm{R}$ & $\mathrm{R}$ & $\mathrm{R}$ & $\mathrm{R}$ \\
IRBLta2-Pi & $\mathrm{R}$ & $\mathrm{R}$ & $\mathrm{R}$ & $\mathrm{R}$ & $\mathrm{R}$ & $\mathrm{R}$ & $\mathrm{R}$ \\
IRBLb-w/co & $\mathrm{S}$ & $\mathrm{S}$ & $\mathrm{S}$ & $\mathrm{S}$ & $\mathrm{R}$ & $\mathrm{S}$ & $\mathrm{S}$ \\
IRBLi-F5 & $\mathrm{S}$ & $\mathrm{R}$ & $\mathrm{R}$ & $\mathrm{R}$ & $\mathrm{R}$ & $\mathrm{R}$ & $\mathrm{R}$ \\
IRBLkm-Ts & $\mathrm{S}$ & $\mathrm{S}$ & $\mathrm{S}$ & $\mathrm{S}$ & $\mathrm{S}$ & $\mathrm{S}$ & $\mathrm{S}$ \\
IRBLz-Fu & $\mathrm{S}$ & $\mathrm{S}$ & $\mathrm{S}$ & $\mathrm{S}$ & $\mathrm{S}$ & $\mathrm{S}$ & $\mathrm{S}$ \\
\hline Races & $\mathrm{A}$ & $\mathrm{B}$ & $\mathrm{B}$ & $\mathrm{B}$ & $\mathrm{C}$ & $\mathrm{B}$ & $\mathrm{B}$ \\
\hline
\end{tabular}

$\mathrm{S}=$ Susceptible, $\mathrm{R}=$ Resistant, DAK = Dakawa, KAH = Kahama, KAP = Kapwili, KIK = Kikusya, MOS = Moshi and MSU $=$ Msufini.

All P. oryzae strains were not pathogenic on IRBLk-Ka, IRBLkp-K60, IRBLa-C, IRBLta2-Pi, St and IRBLt-K59. All strains (KAD, KAH, KAP, MOS, SUA, KIK and MSU) produced susceptible reaction only on rice differentials IRBLKm-Ts and IRBLz-Fu. The strain from Moshi was not able to infect IRBLb-w/co, while the rice differential was susceptible to all other $P$. oryze strains. Dakawa strain was pathogenic on IRBLi-F5 while other strains were not.

However, all seven $P$. oryzae strains were pathogenic on IRBLkm-Ts and IRBLz-Fu (Table 1). Similar contradicting results have been reported by [43] when studying molecular marker application for rice blast resistance selection on the double haploid rice population. The virulence of the strain obtained have been reported to be strongly influenced by the varieties from where they were isolated [4].

On the basis of the reaction of the ten international differentials, three races (A, B and $\mathrm{C}$ ) of $P$. oryzae were identified (Table 1). Most of the strains belonged to race $B$ (Table 1). Race A and C consisted of a single strain each. Race $\mathrm{C}$ characterized by resistant reaction of the eight international differentials viz; IRBLk-Ka, IRBLa-C, St, IRBLkp-K60, IRBLt-K59, IRBLta2-Pi, IRBLb-w/co and IRBLi-F5. Race B was characterized by susceptible reaction of three differentials IRBLb-w/co, IRBLkm-Ts and IRBLz$\mathrm{Fu}$ followed by race $\mathrm{A}$ which was characterized by susceptible reaction of four differentials.

Pathogenic variation has been cited as the principal cause for the frequent breakdown of resistance shortly after monoconidial sub-cultures. [12] also found that the strains of $P$. oryzae from the same lesion may differ in pathogenicity, and single-spore sub-cultures may also differ in pathogenicity from the original single-spore cultures. Strains from each rice-growing region were limited; therefore, further collection and evaluation of strains are needed to confirm the findings of this study.

The similarity coefficients of $P$. oryzae strains used in this study varied from 0.3 to 1.0 and clustered broadly into two groups (Figure 3 ). The average similarities within the cluster of strains in group one was significantly smaller than the average similarities among strains from group two. However, on the basis of the reaction types either pathogenic or nonpathogenic, the seven strains were grouped into three different pathotypes (Figure 3).

Pyricularia oryzae strains induced differential reaction on IRBLb-w/co, IRBLi-F5, IRBLkm-Ts and IRBLz-Fu. Rice differentials IRBLb-w/co, IRBLi-F5, IRBLkm-Ts and IRBLz-Fu were susceptible to all strains. This agrees with findings reported by [42] when identifying rice blast disease resistance genes using international rice differential varieties that of $P$. oryzae strains can genetically remain stable in the resistance cultivar.

Results showed that both pathogenic and non-pathogenic strains were clustered together in a closely related group. In the present study, the strains were designated into two main groups (Figure 3 ). The first group was designed as slightly virulent strains consisting of MOS strain. Five strains, KAP, SUA, MSU, KIK and KAH were assigned to group two designated as moderately virulent strains with the remaining DAK strains assigned to group three, a severely virulent strains. The present investigation revealed that these three groups of $P$. oryzae strains infected all the International rice differentials. These strains could overcome a great number of resistance genes because each of the differential genotype possessed different resistance gene against rice blast disease. 
International Journal of Science and Research (IJSR)

ISSN (Online): 2319-7064

Index Copernicus Value (2013): 6.14 | Impact Factor (2014): 5.611

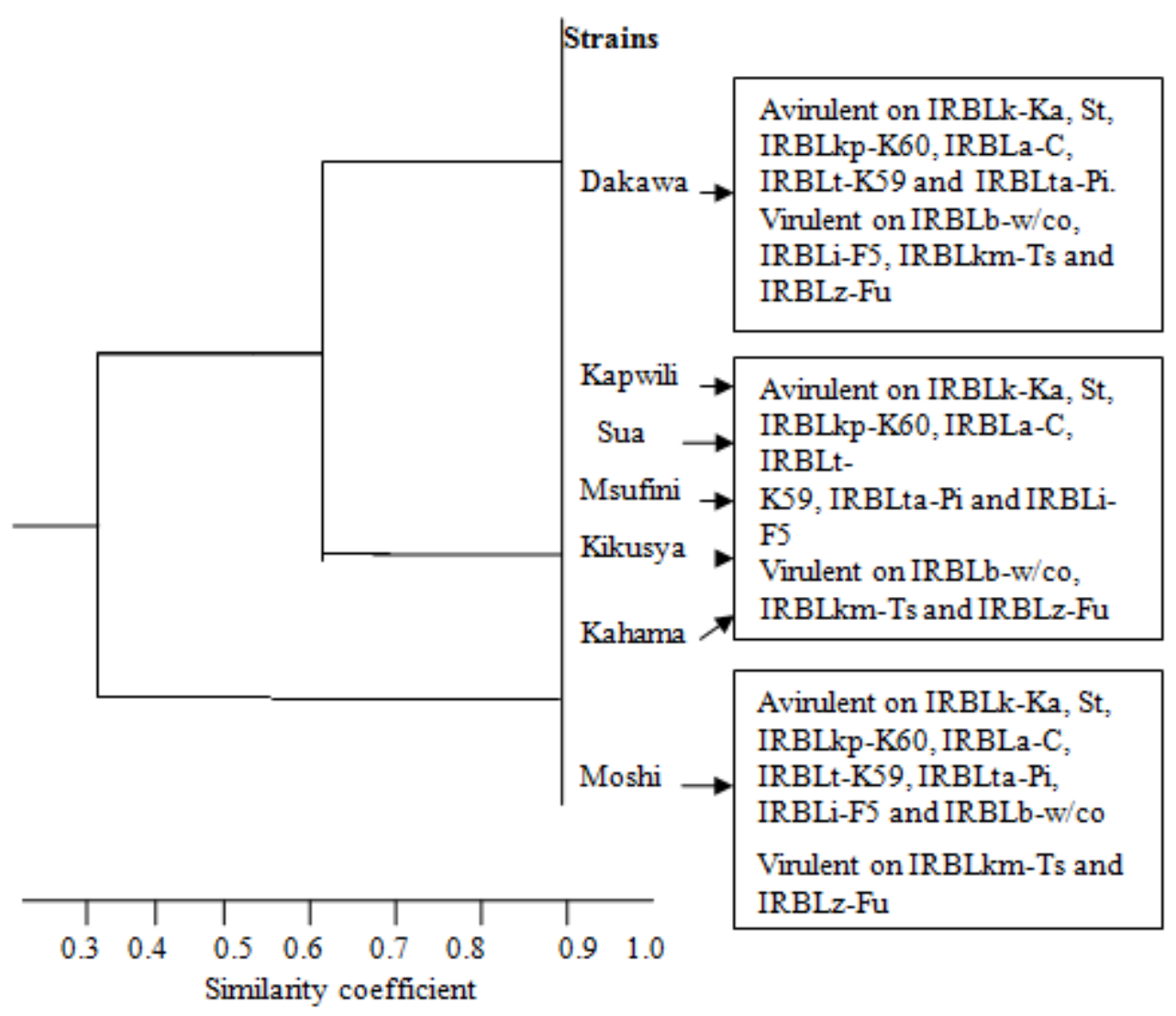

Differences in pathogenicity between individual strains have been used for a long time to determine pathogenic variation of P. oryzae [34].

In pathotype one, only Dakawa strain was included, while a maximum of five strains (Kapwili, Sua, Kikusya, Msufini and Kahama) were included in pathotype 2 (Figure 4) and the remaining Moshi strains were grouped in pathotype three. Among the host differentials, IRBLk-Ka, St, IRBLkpK60, IRBLa-C, IRBLt-K59 and IRBLta-Pi showed resistance to all seven strains and IRBLi-F5 to five strains followed by IRBLb-w/co being resistant to one strain.

These results are supported by the study of [21] on the virulence characteristic analysis and identification of new pathotypes of the rice blast fungus (Magnaporthe grisea) in India.

Strains of $P$. oryzae were grouped in different pathotypes based on their reaction on rice varieties known to have sources of resistance. However, the resistance genes Pik, , Pik-p, Pii, Pita-2 and Pit remained effective against rice blast strains while genes $P i k-m$ and $P i z$ were not effective against the disease. Such observations have also been reported by [4], [7], [10], [27].

\subsection{Characterization of Pyricularia oryzae strains using molecular technique}

Molecular markers have been used widely to characterize fungal plant pathogen populations, in particular for the characterization of $P$. oryzae. Seven strains of $P$. oryzae were analyzed for genetic variation using five primers which included Bt1a and Bt1b, CAL-228F and CAL-737R, ACT512F and ACT-783R, ITS1 and ITS4, Pot2-1 and Pot2-2 (Table 2). Primers tested were specific to P. oryzae from which they were designed.

Table 2: Pyricularia oryzae primers for reductase gene amplification used in the current study.

\begin{tabular}{ll|}
\hline Primer & Primer sequence (5' $\mathbf{- 3}$ ') \\
Forward - ACT-512 & ATGTGCAAGGCCGGTTTCGC \\
Reverse - ACT-783 & TACGAGTCCTTCTGGCCCAT \\
Forward - Bt1a & TTCCCCCGTCTCCACTTCTTCATG \\
Reverse - Bt1b & GACGAGATCGTTCATGTTGAACTC \\
Forward - CAL-228 & GAGTTCAAGGAGGCCTTCTCCC \\
Reverse - CAL-737 & CATCTTTCTGGCCATCATGG \\
Forward - ITS1 & TCGGTAGGTGAACCTGCGG \\
Reverse - ITS4 & TCCTCCGCTTATTGATATGC \\
Forward - Pot2-1 & CGGAAGCCCTAAAGCTGTTT \\
Reverse - Pot2-2 & CCCTCATTCGTCACACGTTC \\
\hline
\end{tabular}




\section{International Journal of Science and Research (IJSR) \\ ISSN (Online): 2319-7064}

Index Copernicus Value (2013): 6.14 | Impact Factor (2014): 5.611

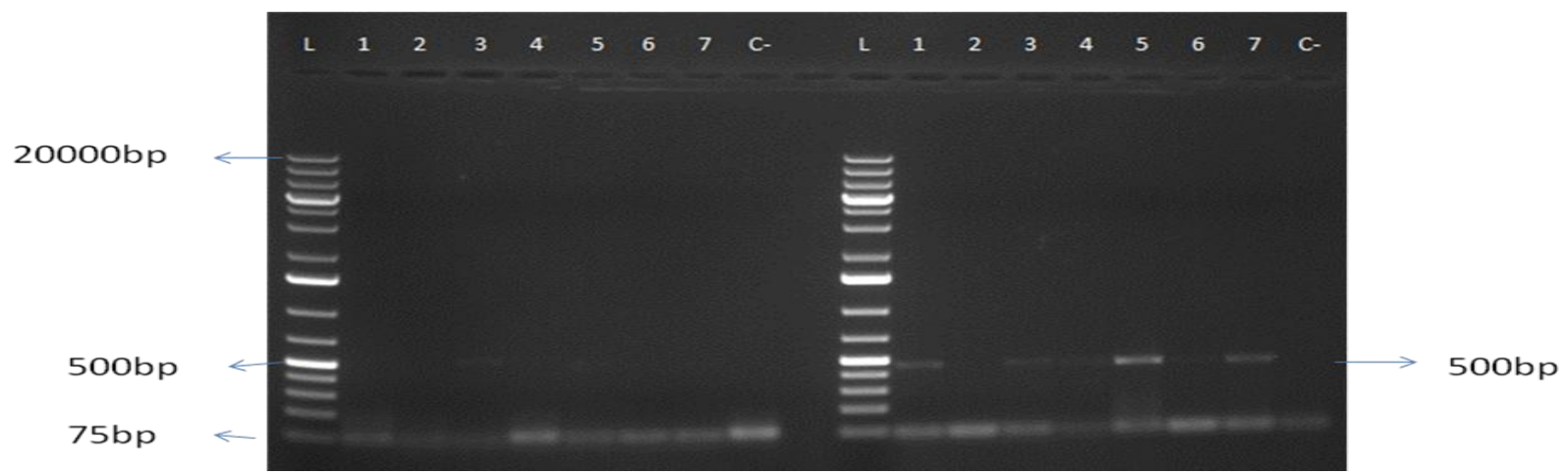

Figure 4: Agarose gel eletrophoresis of PCR amplification products of Pyricularia oryzae genomic DNA using primers BTta \& BTtb (left) and CAL-228F \& CAL-737R (right). Strains from left to right were MSU, SUA, DAK, KAH, KAP, KIK and MOS. $\mathrm{L}=\operatorname{Ladder}(1 \mathrm{~kb}+)$ and $\mathrm{C}=$ control. Arrows indicate the two fragments that are characteristic of $P$. oryzae. Molecular sizes are shown in base pairs (bp).

Of the ten (10) primers used, Bt1a and Bt1b, Pot2-1 and Pot2-2 did not amplify DNA from all $P$. oryzae strains, suggesting problems with the primers' specificity for the Pyricularia oryzae pathogen. However, the primers CAL228F and CAL-737R amplified genomic DNA of P. oryzae strains MSU, DAK, KAP and MOS while SUA, KAH and KIK strains were not amplified (Figure $4 \& 5$ ).

Furthermore, the primer ACT amplified KAP, KIK and MOS strains while MSU, SUA, DAK and KAH were not amplified. The primers ITS amplified $P$. oryzae strains MSU, SUA, KAH, KAP, KIK and MOS. The P. oryzae strains SUA and KAH were very faintly amplified. The strain DAK was not amplified by both ACT and ITS primers, suggesting lack of similarity with the fungal DNA structure (Figures $4 \&$ 5). Similar results have been reported by [19] in the investigation of an expedited method for isolation of DNA for PCR from Magnaporthe oryzae stored on filter paper, who characterized strains from rice and indicated that the strains of $P$. oryzae attacking rice leaves and panicles were genetically distinct from location to location.
The amplification reactions with the three primers generated polymorphic bands. A single $500 \mathrm{bp}$ product was exhibited by all the strains of $P$. oryzae amplified by CAL-228F \& CAL-737R (Figure 4). [23] reported similar results when they were identifying blast resistance expression in rice genotypes using molecular markers (RAPD \& SCAR). They found that most of the $P$. oryzae strains identified were polymorphic in nature with band sizes of between 100 and $500 \mathrm{bp}$.

The primers ACT-512 and ACT-783 amplified P. oryzae strains KAP, KIK and MOS collected from Mbeya and Kilimanjaro regions, respectively (Figure 5). Primers ITS 1 and ITS 4 amplified strains MSU, SUA, DAK, KAH, KAP,KIK and MOS of P. oryzae, and strains also appeared similar with polymorphic banding pattern of $550 \mathrm{bp}$. These amplification values were higher than those reported by [23] which ranged of from $40 \mathrm{bp}$ to $420 \mathrm{bp}$. Similar results were reported by [34] using REMAP markers and amplification values ranged from 490 to $600 \mathrm{bp}$.

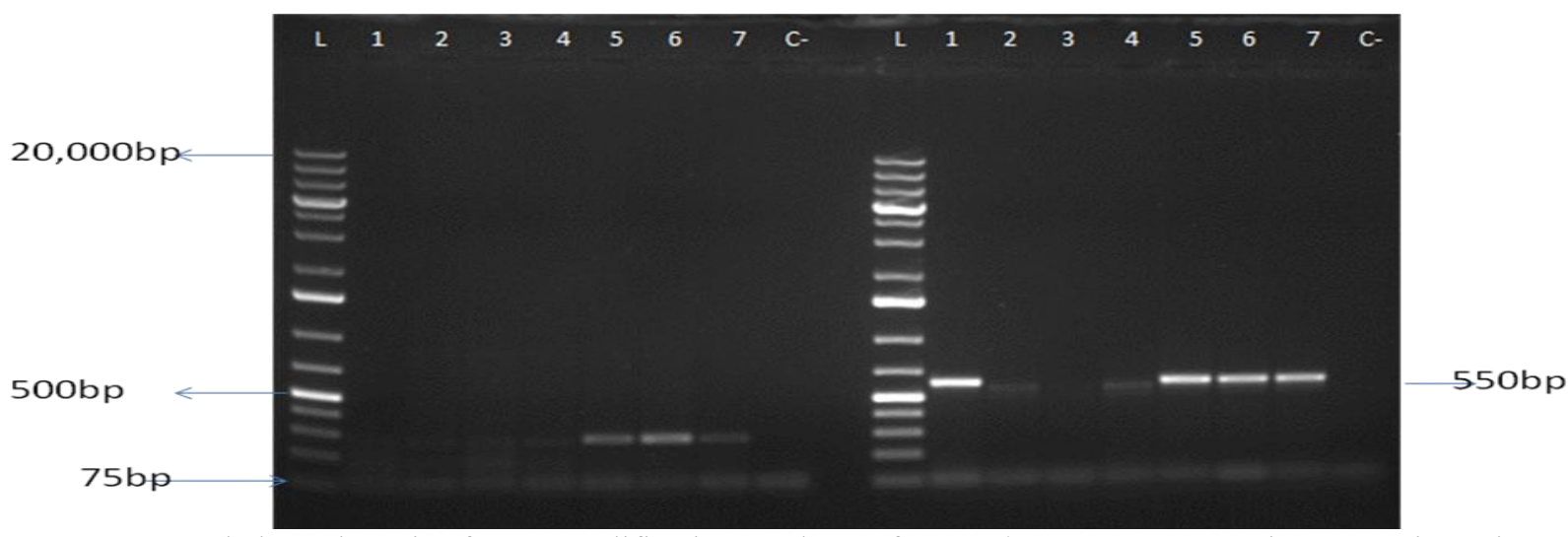

Figure 5: Agarose gel eletrophoresis of PCR amplification products of Pyricularia oryzae genomic DNA using primers ACT512F \& ACT-783 (left) and ITS1 \& ITS4 (right). The P. oryzae strains from left to right in the photograph were MSU, SUA, DAK, KAH, KAP, KIK and MOS, respectively. $\mathrm{L}=$ Ladder $(1 \mathrm{~kb}+)$ and $\mathrm{C}=$ control. Arrows indicate the two fragments that are characteristic of $P$. oryzae. Molecular sizes are shown in base pairs (bp).

The Pyricularia oryzae strains did not show differences in banding patterns. The banding patterns of seven $P$. oryzae strains from major rice growing areas in Tanzania were all similar (Figure $4 \& 5$ ). This study revealed that the $P$. oryzae strains collected from different major rice growing areas of Tanzania were not significantly different genetically.
PCR products of seven $P$. oryzae strains produced a strong band of 550 bp and very weak bands at $\leq 500$ bp (Figures $4 \&$ 5). Pyricularia oryzae strains MOS, KIK, KAP and MSU were amplified by primers ITS1, ITS4, ACT-512, CAL-228 and CAL-737 and produced strong bands of 550bp. This confirmed these isolates to be $P$. oryzae and the PCR with

\section{Volume 4 Issue 11, November 2015}




\section{International Journal of Science and Research (IJSR) \\ ISSN (Online): 2319-7064 \\ Index Copernicus Value (2013): 6.14 | Impact Factor (2014): 5.611}

ITS1, ITS4, ACT-512, CAL-228 and CAL-737 primers proved to be a reliable method to differentiate the rice blast pathogen. The number of amplification products obtained was specific to each primer. Overall, the random amplified polymorphic DNA patterns did not show high level of polymorphism. The results indicate that the $P$. oryzae strains genome were genetically stable, but varied in pathogenic [20], [25], [47]. These results can be used for screening resistance commercial rice varieties for planting in areas where there is high risk of $P$. oryzae infection. This information however, is imperative to develop effective breeding rice varieties resistance to rice blast disease strategies in the country.

\section{Conclusion}

The results of this study indicated that the strains of $P$. oryzae identified greatly differed in pathogenic patterns. Great pathogenic variation was detected in the strains using international rice differential genotypes with different resistance genes. All seven $P$. oryzae strains used were pathogenic on rice differentials Pik-m, Pii and Piz. Based on characterization of $P$. oryzae using International rice differentials, three different races of $P$. oryzae were identified among seven strains. Races $\mathrm{A}$ and $\mathrm{C}$ comprise one strain each, whereas, race B comprises of five strains.

The results of molecular analysis showed no differences in banding patterns between strains from major rice growing areas in Tanzania, indicating that all strains analyzed were genetically homogeneous but pathogenically heterogeneous.

In cluster analysis, the strains were grouped into two main groups showing close relationships in pathogenic variation. The highest pathogenic strains; DAK, KAP, SUA, MSU, KIK and KAH were clustered in the same group showing the close correspondence between them. Pathogenic variation among strains plays an important role in rice blast disease dynamic and consequently, in the success of integrated disease control especially for breeding resistant rice varieties. However, based on the results of present study, both characterization and pathogenic variation of $P$. oryzae strains should be considered when screening of rice germplasm against $P$. oryzae the cause of rice blast disease.

\section{Acknowledgement}

We thank the Eastern African Agricultural Productivity Programme (EAAPP) Tanzania for providing funds for this work. Thanks are due to AfricaRice and the International Rice Research Institute (IRRI) Tanzania for supplying rice plant materials.

\section{References}

[1] A. Anwar, M. A. Teli, G. N. Bhat, G. A. Parray and Wani, "Status of rice blast (Pyricularia grisea), cultivar reaction and races of its causal fungus in temperate agro- ecosystem of Kashmir, India". SAARC Journal Agriculture XII (2), pp. 25-37, 2009.

[2] L. Babujee and S. S. Gnanamanickham, "Molecular tools for characterization of rice blast pathogen
(Magnaporthe grisea) population and molecular marker-assisted breeding for disease resistance". Current Science LXXVIII, pp. 248-257, 2000.

[3] Z. A. Bhat, M. A. Ahangar, G. S. Sanghera and T. Mubarak, "Effect of cultivar, fungicide spray and nitrogen fertilization on management of rice blast under temperate ecosystem, International Journal of Science, Environment and Technology, II (3), pp. 410 - 415, 2013.

[4] J. M. Bonman, T. I. V. D. Dios, J. M. Bandong and E. J. Lee, "Pathogenic variability of monoconidial isolates of Pyricularia oryzae in Korea and in the Philippines". Plant Disease, LXXIV, pp. 127-130, 1987.

[5] B. Bussaban, S. Lumyong, P. Lumyong T. Seelanan, D. C. Park and E. H. C. McKenzie, "Molecular and morphological characterization of Pyricularia and allied genera", Mycologia, XCVII (5), pp. 1002-1011, 2005.

[6] H. L. Chen, B. T. Chen, D. P. Zhang, Y. F. Xie and Q. Zhang, "Pathotypes of Pyricularia grisea in rice fields of central and southern China". Plant Disease, LXXXV, pp. 843-850, 2001.

[7] F. J. Correa-victoria and R. S. Zeigler, "Pathogenic variability in Pyricularia grisea at a rice blast "hotspot" breeding site in Eastern Colombia" Plant Disease, LXXVII, pp. 1029-1035, 1993.

[8] B. C. Couch and L. M. Kohn, "A multilocus gene genealogy concordant with host preference indicates segregation of a new species, Magnaporthe oryzae, from M. grisea”, Mycologia, XCIV, pp. 683-693, 2002.

[9] M. S. Dar, S. Hussain, A. B. Darzi and S. H. Bhat, "Morphological variability among various isolates of Magnaporthe grisea collected from paddy growing areas of Kashmir". International Journal of Pharmaceutical Sciences Review and Research, VIII, pp. 90-92, 2011.

[10] H. D. Dinh, T. Noda and P. V. Du, "Deployment of resistant varieties to blast (Pyricularia grisea) in the Mekong Delta". Omonrice, VII, pp. 132-137, 1999.

[11] M. C. C. Filippi, G. B. Silva, V. L. Silva-Lobo, M. V. C. B. Côrtes, A. J. G. Moraes and A. S. Prabhu, "Leaf blast (Magnaporthe oryzae) suppression and growth promotion by rhizobacteria on aerobic rice in Brazil". Biological Control, LVIII, pp. 160-166, 2011.

[12] M. A. Gad, N. A. Ibrahim and T. C. Bora, "Molecular biodiversity in phytopathogenic fungi, Pyricularia spp." Journal of Biology and Chemistry Research, XXX, pp. (1), pp. 216-226, 2013.

[13] E. E. Gandalera, C. C. Divina and J. D. Dar, "Inhibitory activity of Chaetomium globosum Kunze extract against Philippine strain of Pyricularia oryzae Cavara". Journal of Agricultural Technology, IX (2), pp. 333-348, 2013).

[14] M. U. Ghazanfar, A. Habib and S. T. Sahi, "Screening of rice germplasm against Pyricularia oryzae the cause of rice blast disease". Pakistan Journal of Phytopathology, XXI (1), pp. 41-44, 2009a.

[15] M. S. Hosseini-Moghaddam and J. Soltani, "An investigation on the effects of photoperiod, aging and culture media on vegetative growth and sporulation of rice blast pathogen Pyricularia oryzae". Progress in Biological Sciences, III (2), pp. 135-143, 2013. 


\section{International Journal of Science and Research (IJSR) ISSN (Online): 2319-7064 \\ Index Copernicus Value (2013): 6.14 | Impact Factor (2014): 5.611}

[16] International Rice Research Institute, "Standard Evaluation System for Rice", Inger. Genetic resources center, IRRI, Manila, Philippines, pp. 17, 1996.

[17] International Seed Testing Association, "International Seed Testing Association rules book Zurich". Seed Science and Technology, XIII (2), pp. 299 - 520, 2005.

[18] International Seed Testing Association, "Detection of Pyricularia oryzae on Oryza sativa (Rice)". International Rules for Seed Testing Annexe to chapter 7: Seed Health Testing Methods. International Seed Testing Association (ISTA), Bassersdorf, Switzerland, pp. 7-011, 2014.

[19] Y. Jiaa, Y. A. Wamisheb and B. Zhouc. (In press). An expedited method for isolation of DNA for PCR from Magnaporthe oryzae stored on filter paper. The Crop Journal.

[20] S. Kang and Y. Lee, "Population structure and race variation of the rice blast fungus". The Plant Pathology Journal, XVI (1), pp. 1-8, 2000.

[21] V. Karthikeyan, R. Rajarajan, and S. S. Gnanamanickam, "Virulence characteristic analysis and identification of new pathotypes of rice blast fungus (Magnaporthe grisea) from India". Life Sciences Feed, II (1), pp. 7- 12, 2013.

[22] R. B. Khadka, S. M. Shrestha, H. K. Manandhar, and G. B. K. C. "Pathogenic variability and differential interaction of blast fungus (Pyricularia grisea SACC.) isolates with finger millet lines in Nepal". Nepal Journal of Science and Technology, XIV (2), pp. 1724,2013

[23] A. Kumar, S. Kumar, R. Kumar, V. Kumar, L. Prasad, N. Kumar, and D. Singh, "Identification of blast resistance expression in rice genotypes using molecular markers (RAPD \& SCAR)". African Journal of Biotechnology, IX (24), pp. 3501-3509, 2010.

[24] H. Leung, E. S. Borromeo, M. A. Bernardo and J. L. Notteghem, "Genetic analysis of virulence in the rice blast fungus Magnaporthe grisea". Phytopathology LXXVIII, pp. 1227-1233, 1988.

[25] Y. Li, S. Liang, X. Yan, H. Wang, D. Li, D. M. Soanes, N. J. Talbot, Z. Wang and W. Zhengyi, "Characterization of MoLDB1 required for vegetative growth, infection-related morphogenesis and pathogenicity in the rice blast fungus Magnaporthe oryzae". The American Phytopathological Society XXIII (10), pp. 1260-1274, 2010.

[26] S. B. Mathur and Kongsdal Olga, "Common Laboratory Seed Healthy Testing Methods for Detecting Fungi". Danish Government Institute of Seed Pathology for Developing Countries. Thorvaldsensvej 57, DK-1871 Frderiksberg C, Denmark. pp. 325-328, 2001.

[27] M. T. Noguchi, N. Yasuda and Y. Fujita, "Fitness characters in parasexual recombinants of the rice blast fungus, Pyricularia oryzae". Japan Agriculutral Research Quartely, XLI (2), pp. 123 - 131, 2007.

[28] S.Y. Padmanabhan, N. K. Chakrabarti, S. C. Mathur and J. Veeraraghavan, "Identification of pathogenic races of Pyricularia oryzae in India”. Phytopathology, LX, pp. 1574-1577, 1970.

[29] A. S. Prabhu, C. M. Filippi, L. G. Araujo and J. C. Faria, "Genetic and phenotypic characterization of isolates of Pyricularia grisea from the rice cultivars
EPAGRI 108 and 109 in the State of Tocantins" May, 2002. [Online] Available: http://www.scielo.br/scielo.php?pid=S0100$41582002000600002 \&$ script $=$ sci_arttext. [Accessed May 25, 2011].

[30] A. S. Prabhu, L. G. Araújo, G. B. Silva and M. G. Trindade, "Virulence and rep-PCR analysis of Pyricularia grisea isolates from two Brazilian upland rice cultivars", November 2006. [Online]. Available: http://www.scielo.br/scielo.php?pid=S010041582002000600002\&script $=$ sci_arttext. [Accessed: June 2, 2011].

[31] A. S. Prabhu, M. C. Filippi, G. B. Silva, V. L. SilvaLobo and O. P. Morais, "An unprecedented outbreak of rice blast on a newly released cultivar BRS Colosso in Brazil". In Proceeding of advances in genetics, genomics and control of rice blast. Springer Science, Netherlands, pp. 257-267, 2009.

[32] M. S. Prasad, B. A. Kanthi, S. M. Balachandran, M. Seshumadhav, K. M. Mohan and B. C. Viraktamath, "Molecular mapping of rice blast resistance gene Pi1(t) in the elite indica variety Samba mahsuri". World Journal Microbiol Biotechnology, XXV, pp. 17651769, 2009.

[33] R. Rathour, B. M. Singh and P. Plaha, "Virulence structure of the Magnaporthe grisea rice population from the Northwestern Himalayas". Phytoparasitica, XXXIV (3), pp. 281-291, 2006.

[34] D. Srivastava, M. Shamim, D. Kumar, P. Pandey, N. A. Khan and K. N. Singh, "Morphological and molecular characterization of Pyricularia oryzae causing blast disease in rice (Oryza sativa) from North India". International Journal of Scientific and Research Publications, IV, pp. 1-9, 2014.

[35] S. L. Sukanya, D. Yamini and S. K. Fathima, "Ecofriendly management of Pyricularia oryzae - The causal agent of blast of paddy". Current Botany, II (8), pp. 46-49, 2011.

[36] Thinlay, R. S. Zeigler and M. R. Finckh, "Pathogenic Variability of Pyricularia grisea from the High- and Mid-Elevation Zones of Bhutan". The American Phytopathological Society, XC (6), pp. 621-628, 2000.

[37] A. S. Urashima, "Variation in virulence in the rice blast fungus Magnaporthe grisea in Sao Paulo State" January 2002. [Online]. Available: http://dx.doi.org/10.1590/S0100-204X2002000100015. [Accessed: June 4, 2014].

[38] S. Urayama, S. Kato, Y. Suzuki, N. Aoki, M. T. Le, T. Arie, T. Teraoka, T. Fukuhara and H. Moriyama, "Mycoviruses related to chrysovirus affect vegetative growth in the rice blast fungus Magnaporthe oryzae". Journal of General Virology, XCI, pp. 3085-3094, 2010.

[39] B. Valent, M. S. Crawford and C. G. Weaver, "Genetic studies of fertility and pathogenicity in Magnaporthe grisea (Pyricularia oryzae)". Iowa State Journal Resourse, LX, pp. 569-594, 1986.

[40] P. Vanaraj, S. Kandasamy, S. Ambalavanan, R. Ramalingam and R. Sabariyappan, "Variability in Pyricularia oryzae from different rice growing regions of Tamil Nadu, India". African Journal of Microbiology Research, VII (26), pp. 3379-3388, 2013. 


\section{International Journal of Science and Research (IJSR) \\ ISSN (Online): 2319-7064}

Index Copernicus Value (2013): 6.14 | Impact Factor (2014): 5.611

[41] J. Veeraraghavan "Specialization in pathogenicity of Pyricularia oryzae Cav." In Proceedings Indian nation Academic, Cuttack, pp. 300-307, 1986.

[42] J. C. Wang, Y. Jiab, J. W. Wen, W. P. Liu, X. M. Liu, L. Li, Z. Y. Jiang, J. H. Zhang, X. L. Guo and J. P. Ren, "Identification of rice blast resistance genes using international monogenic differentials". Crop Protection, XLV, pp. 109-116, 2013.

[43] G. Windarsih, D. W. Utami and U. Widyastuti, "Molecular markers application for blast resistance selection on the double haploid rice population". Makara Journal Science, XVIII (2), pp. 31-41, 2014.

[44] R. S. Zeigler, "Recombination in Magnaporthe grisea." Annual review of phytopathology, XXXVI, pp. 249275, 1998.

[45] R. S. Zeigler, R. P. Scott, H. Leung, A. A. Bordeos, J. Kumar, and R. J. Nelson, "Evidence of parasexual exchange of DNA in rice blast fungus challenges its exclusive clonality". Phytopathology, LXXXVII, pp. 284-294, 1997.

[46] C. Zhang, X. Huang, J. Wang and M. Zhou, "Resistance development in rice blast disease caused by Magnaporthe grisea to tricyclazole". Pesticide Biochemistry and Physiology, XCIV, pp. 43-47, 2009.

[47] E. Zhou, Y. Jia, P. Singh, J. C. Correll and F. N. Lee, "Instability of the Magnaporthe oryzae avirulence gene AVR-Pita virulence". Fungal Genetics and biology, XLIV, pp. 1024-1034, 2007.

\section{Author Profile}

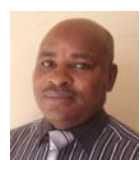

Charles J. Chuwa received the Bsc, Msc and $\mathrm{PhD}$ degree in Agriculture from Sokoine University of Agriculture in 1997, 2004 and 2015, respectively. During 2004 to- date, he is a researcher in the Ministry of Agriculture and Food security of Tanzania. 